\title{
Review
}

\section{Biomonitoring: An appealing tool for assessment of metal pollution in the aquatic ecosystem}

\author{
Qunfang Zhou, Jianbin Zhang, Jianjie Fu, Jianbo Shi, Guibin Jiang* \\ State Key Laboratory of Environmental Chemistry and Ecotoxicology, Research Center for Eco-Environmental Sciences, Chinese Academy \\ of Sciences, Beijing 100085, China
}

\section{A R T I C L E I N F O}

\section{Article history:}

Received 17 August 2007

Received in revised form

7 November 2007

Accepted 7 November 2007

Published on line 19 November 2007

\section{Keywords:}

Biomonitoring

Metal pollution

Aquatic ecosystem

\begin{abstract}
A B S T R A C T
Wide occurrence of aquatic metal pollution has caused much attention. Biomonitoring offers an appealing tool for the assessment of metal pollution in aquatic ecosystem. The bioindicators including algae, macrophyte, zooplankton, insect, bivalve mollusks, gastropod, fish, amphibian and others are enumerated and compared for their advantages and disadvantages in practical biomonitoring of aquatic metal pollution. The common biomonitoring techniques classified as bioaccumulation, biochemical alterations, morphological and behavior observation, population- and community-level approaches and modeling are discussed. The potential applications of biomonitoring are proposed to mainly include evaluation of actual aquatic metal pollution, bioremediation, toxicology prediction and researches on toxicological mechanism. Further perspectives are made for the biomonitoring of metal pollution in aquatic ecosystem.
\end{abstract}

() 2007 Elsevier B.V. All rights reserved.

\section{Contents}

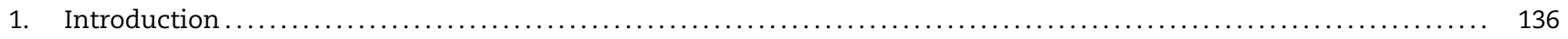

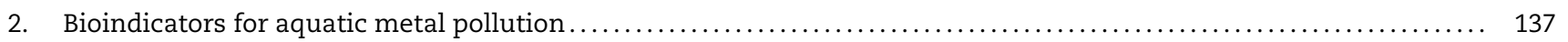

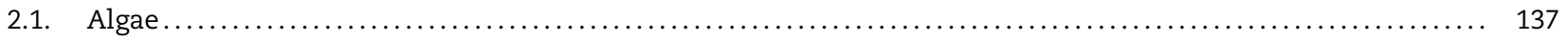

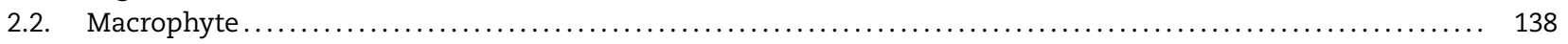

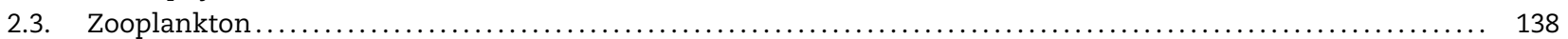

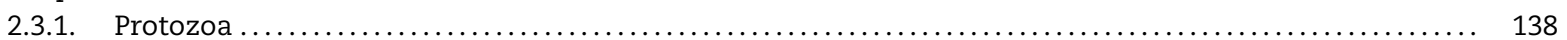

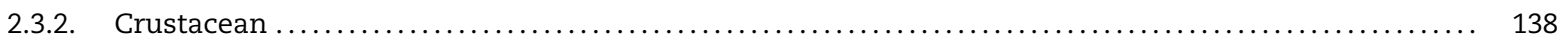

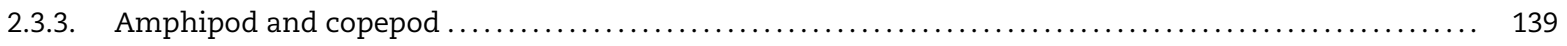

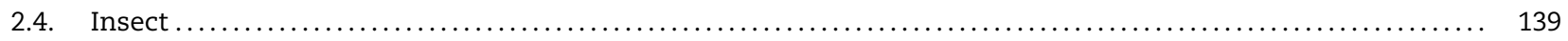

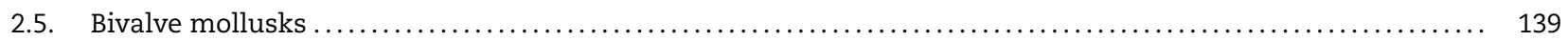

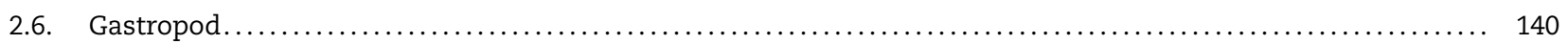

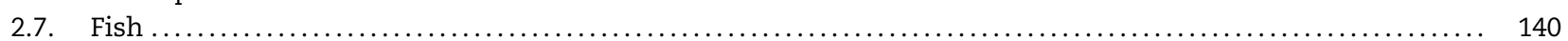

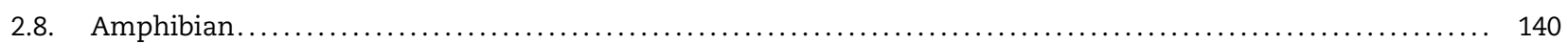

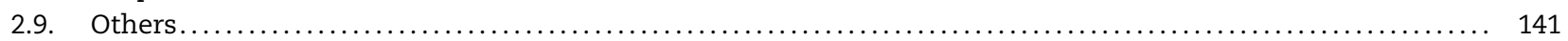

\footnotetext{
* Corresponding author. Tel.: +86 10 62849179; fax: +86 1062849179.

E-mail address: gbjiang@rcees.ac.cn (G. Jiang). 


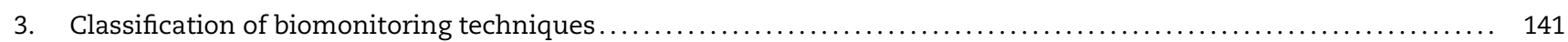

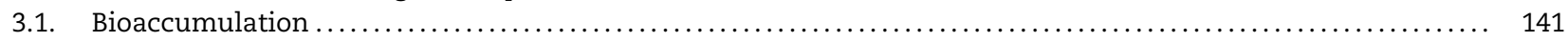

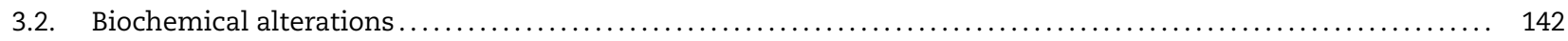

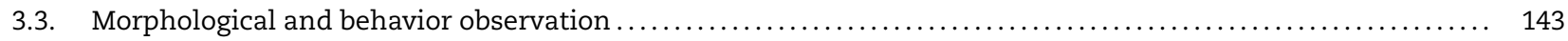

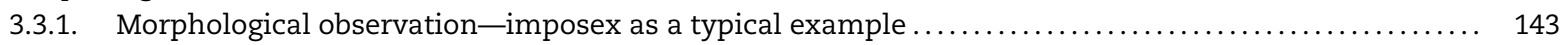

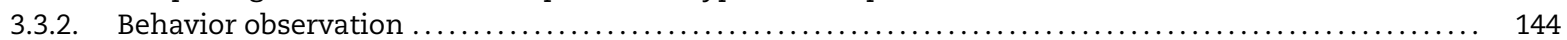

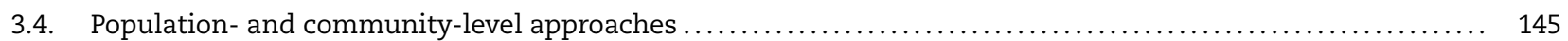

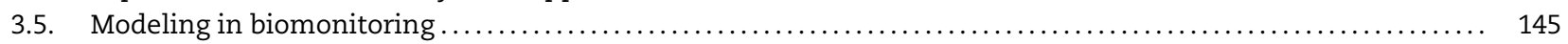

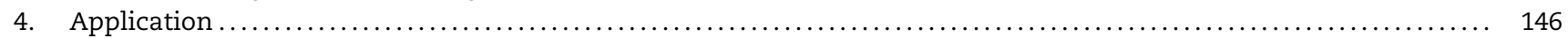

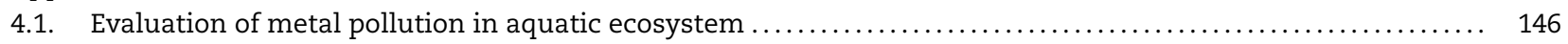

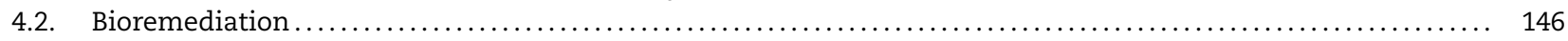

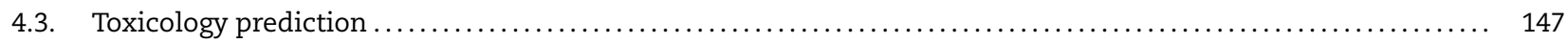

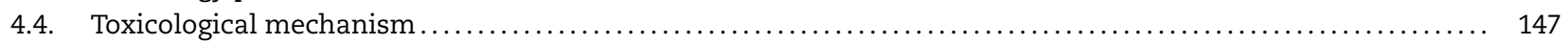

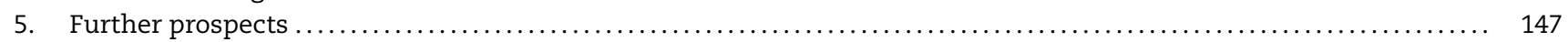

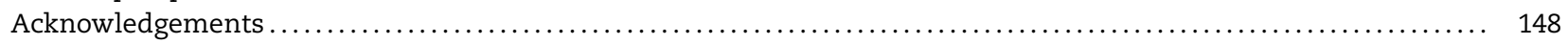

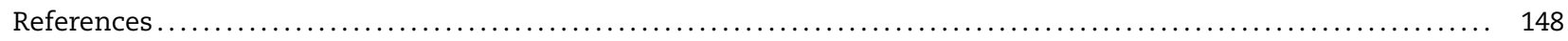

\section{Introduction}

More and more attention has been drawn due to the wide occurrence of metal pollution in aquatic system. Some heavy metals may transform into the persistent metallic compounds with high toxicity, which can be bioaccumulated in the organisms, magnified in the food chain, thus threatening human health [1]. Various harmful effects including abnormal development of fetus, procreation failure, and immunodeficiency has exhibited due to aquatic metal exposure [2]. Monitoring and prevention of heavy metal pollution is one of the hot topics in environmental researches.

Heavy metals in aquatic system can be naturally produced by the slow leaching from soil/rock to water, which are usually at low levels, causing no serious deleterious effects on human health [2]. The development of industry and agriculture promotes the rapid increase of environmental metal pollution. Aquatic heavy metal pollution usually represents high levels of $\mathrm{Hg}, \mathrm{Cr}, \mathrm{Pb}, \mathrm{Cd}, \mathrm{Cu}, \mathrm{Zn}, \mathrm{Ni}$ etc. in water system $[3,4]$. The anthropogenic activities such as discharge of heavy metal wastewater contribute to the predominant causation. The wastewater mainly origins from mining, mill run, metallurgy, plating, chemical plant, curry and paper making industry. Although some metallic compounds can be strongly absorbed onto the suspended particles and sediments, they are able to be released into the water under the suitable conditions such as $\mathrm{pH}$ values and Eh, leading to further contamination of aquatic metal [5]. Some heavy metal including $\mathrm{Hg}, \mathrm{Cr}, \mathrm{Cd}$, $\mathrm{Ni}, \mathrm{Cu}, \mathrm{Pb}$ etc. introduced into environmental water system may pose high toxicities on the aquatic organisms [6]. As an example, cadmium is a priority environmental contaminant with consequences for human health and the maintenance of bio-diversity in affected ecosystems and the timeliness of a broader, ecosystem-based approach to cadmium research is highlighted based on the overview of recent developments in the field by Campbell [7].

Wide occurrence of metal pollution exists worldwide now, including China. For example, investigations on Yangtze River showed the occurrence of the various levels of heavy metal in alongshore-aquatic areas with the predominant elements of $\mathrm{Zn}, \mathrm{Pb}, \mathrm{Cd}, \mathrm{Cu}, \mathrm{Cr}$. Some elements with high affinity to sulfur atoms such as $\mathrm{Cd}, \mathrm{Pb}, \mathrm{Hg}$ and $\mathrm{Cu}$ detected in Yangtze River might produce the potential toxicity [8]. Survey on the water quality in Shanghai City showed that Cd was the main pollutant, while Hg was at the second highest level. Determination of $\mathrm{Cu}, \mathrm{Pb}, \mathrm{Zn}$ and $\mathrm{Cd}$ in the surface sediments in Huangpu River indicated that the level of $\mathrm{Pb}$ in the mainstream was 2 folds higher than the national water quality standard. Serious pollution of $\mathrm{Cu}, \mathrm{Zn}, \mathrm{Cd}$ and $\mathrm{Pb}$ was found in 9 branch rivers, wherein 100,75 , and $62.5 \%$ of samples contained the high levels of $\mathrm{Pb}$, $\mathrm{Cd}$ and $\mathrm{Hg}$, respectively, which exceeded the corresponding national water quality standard values in Suzhou River [9]. Different levels of various metal pollutants are reported in many other inland and marine water systems in China [10].

Considering of the use of some rivers and lakes as water supplies, threaten are thus posed on human health via drinking water, polluted vegetable and foodstuff etc. besides the disruption of the natural environment.

Chemical analysis of the environment matrix such as water, sediment is the most direct approach to reveal the heavy metal pollution status in the environment, while it cannot afford the powerful evidence on the integrated influence and possible toxicity of such pollution on the organisms and ecosystem. Biomonitoring is a scientific technique for assessing environment including human exposures to natural and synthetic chemicals, based on sampling and analysis of an individual organism's tissues and fluids. This technique takes advantage of the knowledge that chemicals that have entered the organisms leave markers reflecting this exposure. The marker may be the chemical itself. It may also be a breakdown product of the chemical or some biological changes in the organisms that is a result of the action of the chemical on the individual. The results of these measurements provide information about the amounts of natural and man-made chemicals that have entered and remained in the organisms and the corresponding effects induced. Due to the consistency between the selected organisms and the corresponding living space, biomonitoring can directly offer the data on the potential effects and actual integrated toxicities of pollutants, reflecting the corresponding deleterious degree in the environment. Precaution may be drawn based on the sensitive biomonitoring of chronic effects induced at low dose of pollutants for long-term exposure. These characters 
endowed biomonitoring with attractive advantages of wide practicability, high sensitivity and high integration, which the conventional chemical analysis is lack of [11].

For the biomonitoring of aquatic pollution including heavy metal, the organisms in the given aquatic systems are sampled for the analysis of various biological responses to chemical exposures. Suitable bioindicators usually give great help to the biomonitoring. A perfect bioindicator is expected to have the following characters: (1) it can accumulate high levels of pollutants without death; (2) it lives in a sessile style, thus definitely representing the local pollution; (3) it has enough abundance and wide distribution for the repetitious sampling and comparison; (4) its life is long enough for the comparison between various ages; (5) it can afford suitable target tissue or cell for the further research at microcosmic level; (6) easy sampling and easy raising in the lab; (7) it keeps alive in water; (8) it occupy the important position in food chain; (9) well dose-effect relationship can be observed in it [12]. As it is too rigorous to find such bioindicator for biomonitoring, the candidate bioindicator with several characters is practicable according to the specific monitoring purpose. Abundant organisms living in water system such as plankton, sedentary benthos, fish and bacteria promise the feasibility of the biomonitoring methods. As water quality directly affects their population, species, abundance and living behavior, they may act as the bioindicators for the evaluation of water pollution.

The common biomonitoring methods for aquatic metal pollution include biota population, bacteria test, acute toxicity assay, chronic toxicity assay and residue analysis etc. The method of biota population is usually performed by counting the species and amounts of various organisms in the tested water system. Many bacteria live in surface water, ground water, and other natural environmental water, which offers the possibility for water quality assessment especially for hygiene using bacteria test. Fish and algae are usually used for the acute toxicity assay of pollutants such as heavy metal. The data on half lethal or effect concentration ( $\mathrm{LC}_{50}$ or $\mathrm{EC}_{50}$ ) obtained from these assays can serve as the powerful evidence for the enactment of water quality standards for industrial wastewater discharge regarding various pollutants. It can also be used for the risk assessment of the pollution levels of the water bodies, estimation of water treatment performance etc. Researches on chronic toxicity of pollutants at low levels may range from molecular reaction to individual alterations, including genetic toxicity, embryo toxicity, histopathological alteration, physiological changes and behavior abnormality etc. Biomonitoring using chronic toxicity assay may sensitively indicate the pollution stress posed by the pollutants at sublethal levels. Residue analysis can afford the information on the accumulation, distribution and transfer properties of the pollutants in the target organisms by the chemical analysis due to the occurrence of bioaccumulation and biomaginification for many chemicals in aquatic organisms. Other methods like productivity determination can also reflect aquatic pollution by measuring the chlorophyll contents, photosynthesis, nitrogen fixation in aquatic plants [13].

When compared with the conventional chemical analysis of aquatic environmental matrix, i.e. water and sediment, biomonitoring exhibits obvious predominance as follows: biomonitoring (1) reveals the subtle biological changes of organisms affected by exogenous chemicals, which is usually missed by the conventional chemical analysis; (2) reveals the integrated effects of the complex pollutants on the organisms in the environment; (3) has high sensitivity due to the rapid responses induced in the organisms exposed to pollutants, which helps to the declare of the precaution; (4) realizes the monitoring of the pollutants at low levels which were below the detection limits of the instrumental analytical techniques due to the occurrence of the chronic toxicities of the pollutants in the organisms under long-term exposure; (5) allows widely sampling even at remote areas; (6) avoids the limits of the convention chemical analysis such as continuous sampling, needs of expensive instruments. As an appealing tool, biomonitoring exerts unparalleled functions in the evaluation of environmental pollution, especially for the metal pollution in aquatic ecosystem.

\section{Bioindicators for aquatic metal pollution}

The typical method for biomonitoring is based on bioindicators. As shown in a review concerned with the used of bioindicators by Burger [14], over $40 \%$ of the bioindicator papers were about metal pollution, wherein plants, invertebrates, fish, mammals were the dominant used bioindicator species. For aquatic metal pollution, the common used bioindicators mainly contained organisms including plankton, insect, mollusks, fish, plant, bird etc. Each bioindicator shows the special merits for the biomonitoring of metal pollution in aquatic ecosystem when compared to the others.

\subsection{Algae}

The aquatic algae as the important elementary producers in marine and inland water plays key role to the whole ecosystem. The algae species and amounts can directly reflect the water quality. Heavy metal exposure can cause the disturbance of normal metabolism and biological function, inhibition of photosynthesis, reduction of cytochrome, cellular mutation, putrescence, even death in algae. More importantly, once heavy metal pollutants are accumulated in these organisms, they enter the food chain and may pose serious threaten to animals and human health through biomaginification. Water pollution type and level can be accurately identified by analyzing the species, amounts, physiological and biological responses and residue contents. Algae may not only be significant for biomonitoring studies and could also be a useful phytoremediation technology to restore water quality due to high bioaccumulation abilities.

As an example, a purified strain of algae (Chlorella ellipsoidea) in a pond near the plating factory was reported to exhibit growth inhibition due to $\mathrm{Cu}, \mathrm{Zn}, \mathrm{Ni}$ and $\mathrm{Cd}$ exposure. Negative correlation existed between the contents of chlorophyll A and heavy metal levels. C. ellipsoidea also showed different toxicity response to different metal speciation exposure. Obvious effects on growth, protein contents and ATP levels of the algae could be induced, which thus make this species a suitable bioindicator in the monitoring of aquatic metal pollution. High accumulation ability of the algae for 
heavy metal made it possible for its use in heavy metal wastewater treatment [15].

Although significant results have been obtained based on algae biomonitoring, limited use of such species is expected in the actual investigations due to some of their biological characters. The small individual makes it difficult to isolate enough amount of purebred strain. The complexity of phytoplankton communities makes the monitoring data sinuous for the actual evaluation.

\subsection{Macrophyte}

Sedentary macrophyte as the bioindicator has some advantages such as high tolerance to aquatic metal pollution, convenience for sampling, large individuals and easy to realize laboratory raise. The toxicity in aquatic plants exposed to heavy metal mainly included cellular ultrastructural alterations, photosynthesis inhibition, respiration ability changes, growth inhibition etc. Metal accumulation in the plants is common investigated for the biomonitoring of aquatic pollution.

Plants and algae growing in lake Nainital (U.P., India) accumulated appreciable amount of metals and water roots of Salix was more efficient than others, which may be use for the biomonitoring of $\mathrm{Cr}, \mathrm{Cu}, \mathrm{Fe}, \mathrm{Mn}, \mathrm{Ni}, \mathrm{Pb}$ and $\mathrm{Zn}$ found in water, especially for those like $\mathrm{Fe}, \mathrm{Pb}$ and $\mathrm{Ni}$ higher than the recommended maximum permissible limits. A correlation between the accumulation of heavy metals in the aquatic moss Fontinalis antipyretica and the degrees in the water was established for $\mathrm{Zn}$ and $\mathrm{Cd}$, showing the suitability of this species as a bioindicator for heavy metals [16]. Significant difference in accumulation rate of some metals like $\mathrm{Zn}, \mathrm{Cu}$ and $\mathrm{Ni}$ in different plant organs shows more accumulation in some organs like roots than others [17]. A positive correlation was also found between phytochelatin levels and Cd levels in the moss samples, which confirmed the biochemical response to stress as biomarker for heavy metal pollution at field aquatic locations [18].

Some factors, however, limit the application of macrophytes as bioindicator. For example, metabolic ability of the exposed macrophyte may weaken the effects of metal pollutants. Interactions occurring among various metal ions accumulated in macrophytes may disrupt the expected responses. Growth inhibition of macrophytes induced by pollutants can affect the accurate conclusion to some extent. Different growth rates may exist for the same macrophyte species living in different area, thus weakening its ability for the biomonitoring of aquatic metal pollution.

\subsection{Zooplankton}

Zooplankton containing protozoa, crustacean, amphipod, copepod etc. comprises the important component of aquatic ecosystem. Many zooplankton species can accumulate and metabolize pollutants, which offer the possibility for its use in biomonitoring of water quality. Researches on sedentary entomic communities including Ephemeriptera, Plecoptera and Trichoptera (abbreviated as EPT index) have been carried out for many years in UK, Germany and America.
Wherein, Shannon diversity index, Simposon index and Margalef index are involved. Integrated evaluation of water quality can be effectively made using these indexes. A case study performed by $\mathrm{Xu}$ et al. showed that the alterations of configuration and function parameters in zooplanktons from Lean River and Poyang Lake, Jiangxi Province were statistical correlative with aquatic heavy metal contents. The regressive relationship existed between the diversity of communities and $\mathrm{Cu}$ levels [19]. Some molecular biological techniques can also be use for the specific detection of aquatic metal. For example, $\mathrm{Hg}$ reductase gene of microbe communities can be used for the monitoring of $\mathrm{Hg}$ contamination in the water using slot-blot hybridization [20]. Various zooplankton species show their special advantages in the actual biomonitoring researches.

\subsubsection{Protozoa}

Protozoa is an important component in food webs in the aquatic ecosystem, and exhibits many of the characteristics of structure and function of entire aquatic ecosystems. Simple experimental devices and convenient sampling equipments are required for protozoa assay. Based on its species diversity, configuration particularity and distribution characters, protozoa may serve as the perfect bioindicator. The unicellular protozoa closely contacts to the surrounding environment and shows high sensitive to ambient aquatic pollution due to their simple construction, small individual, large relative surface, weak self-protection. Because of the high reproduce rate, it is feasible to evaluate the effects of the toxicants on the growth, reproduce, metabolism and other biochemical process of several generations of the protozoa in short time, which takes several days, months, even years for superior animal assays. Protozoa and other microorganisms consist of the main components of the biomass in many aquatic ecosystems based on the species and weight counting per unit area or volume. The tolerance and response of aquatic biota to ambient pollution can be represented by protozoa out of question rather than other organisms such as fish. Most of protozoa species are worldwide distributed and not restricted by seasonal variations and regional discrepancies. Total 108 of protozoa species in Lough Neagh Lake, England and 128 in Stechlin, Germany are also found in freshwater in China [21]. Biomonitoring of these congeneric species can thus offer the comparable and credible data.

\subsubsection{Crustacean}

Daphniidae as the representative of crustacean in biomonitoring of aquatic metal, can sensitive response to harmful substances such as heavy metal, pesticide. The observable responses include growth, fertilization, behavior, morphologic characters and biological alterations [22]. Daphniidae toxicity test is the essential assay for worldwide water quality assessment. Based on the strong phototactic behavior in Daphnia magna [23], it is possible to indicate the water quality. The phototactic index (Ip index) of D. magna decreased rapidly at dose-related exposure to aquatic $\mathrm{Cu}$ and $\mathrm{Cd}$. Being compared with the standard $\mathrm{LC}_{50}$ bioassay, the phototactic index inhibition is a more sensitive toxicology index and can greatly shorten the test time [24]. The lower limit detection concentration $\left(0.0056 \mathrm{mgL}^{-1}\right)$ of $3 \mathrm{~h}$ Ip of Daphnia carinata exposed 
to $\mathrm{Cu}^{2+}$ was lower than $24 \mathrm{~h} \mathrm{LC}_{50}\left(0.031 \mathrm{mgL}^{-1}\right), 48 \mathrm{~h} \mathrm{LC} \mathrm{L}_{50}$ $\left(0.021 \mathrm{mgL}^{-1}\right)$ and $96 \mathrm{~h} \mathrm{LC}_{50}\left(0.006 \mathrm{mgL}^{-1}\right)$ [25]. Very obvious negative correlation between Ip index of Daphnia and the concentrations of $\mathrm{Cr}^{6+}$ in standardized toxicant $\mathrm{K}_{2} \mathrm{Cr}_{2} \mathrm{O}_{7}$ solution $\left(R^{2}=0.9921, P<0.01\right)$ were observed. The detection lower limit of $\mathrm{Cr}^{6+}$ concentration was $0.056 \mathrm{mgL}^{-1}$, and the mean precision reached $15.3 \%$ indicating the high sensitivity, precision and reliability of Daphnia Ip index for water quality monitoring [26]. Ip index method of Daphnia for bioevaluating acute toxicity of chemicals and detecting pollutants in water is efficient, sensitive, economical and quick.

Artemia is widely distributed salt water system worldwide. The abundance in its population offers the possibility of its use as the material for biomonitoring of chemical toxicities. Experimental standards for toxicity test using artemia have been discussed. The biomornitoring method of artemia of phase I to phase II was used to test poisoning level and lethal concentration of $\mathrm{K}_{2} \mathrm{Cr}_{2} \mathrm{O}_{7}, \mathrm{HgCl}_{2}, \mathrm{As}_{2} \mathrm{O}_{3}, \mathrm{KCN}$ and the $24 \mathrm{~h} \mathrm{LC}_{50}$ values were $0.69,0.16,0.96,0.09 \mathrm{mgL}^{-1}$, respectively. The biomonitoring technique based on artemia is easy to master and equipments for the test are very simple [27].

Grass shrimp, Palaemonetes spp. as a bioindicator of anthropogenic impacts reviewed by Key et al. [28] showed much more sensitive to heavy metals compared with estuarine fish. In response to heavy metal exposure, all levels of the biomarkers including cytochrome P-450, hsp, lipid peroxidation (LPx), glutathione, $\alpha \beta$-crystallin, ubiquitin and metallothionein (MT) were significantly elevated in grass shrimp, wherein MT levels were the most sensitive parameter [29]. The standardized testing protocols, ease of collection, identification and culture and high abundance of grass shrimp biomass make it possible as an estuarine bioindicator for aquatic metal pollution, nevertheless, the weakness including length of the generation time and lack of developed biomarkers may limit its practical use in biomonitoring to some extent.

\subsubsection{Amphipod and copepod}

An important precondition for using aquatic invertebrate biomonitors is a quantification of their biological attributes or life-history traits on trace metal levels accumulated under field conditions. Study on the amphipods Themisto libellula and T. abyssorum and the copepod Calanus hyperboreus from the Greenland Sea showed exponential relationships between Cd, $\mathrm{Pb}, \mathrm{Cu}$ and $\mathrm{Ni}$ concentrations and their body length, while for $\mathrm{Zn}$ no length dependency was noted regarding T. libellula. Further, substantial differences between juveniles from the marsupium vs. adults were recorded for both amphipod collectives investigated $\left(0.06-0.21 \mathrm{mg}\right.$ vs. $26-50 \mathrm{mg} \mathrm{Cd} \mathrm{kg}^{-1} \mathrm{dry}$ wt. and $3 \mathrm{mg}$ vs. $\left.26-37 \mathrm{mg} \mathrm{Cu} \mathrm{kg}^{-1}\right)$. Significant differences were also noted for copepods, with juveniles showing, for example, somewhat enhanced Cd levels, but they were not as pronounced as those for amphipods $(0.54-0.67 \mathrm{mg}$ vs. $0.94 \mathrm{mg}$ $\left.\mathrm{Cd} \mathrm{kg}^{-1}\right)$. Trophic transfer and metabolic requirements were potential. The utilization of only adult individuals in routine biomonitoring studies was recommended [30].

Due to its wide occurrence, abundant species, sensitive responses, zooplankton may play key roles as the suitable candidate bioindicator in the biomonitoring of metal pollution in aquatic ecosystem.

\subsection{Insect}

Various insects living in or around the aquatic system can be used for the biomonitoring of aquatic metal pollution. Recent approaches for the developments in aquatic insect biomonitoring was reviewed by Bonada et al. and twelve criteria based on rationale, implementation and performance are defined for an ideal biomonitoring tool used in the comparative analysis of biomonitoring approaches [31]. Based on the analysis of cadmium in several Ischnura elegans (Vander Linden) and surrounding water samples, it has been found that I. elegans exhibited a strong ability of accumulation on cadmium in water. No statistical difference among the contents of heavy metal existed in male adult I. elegans from same sites at the same time, suggesting that the organism be an indicator for contamination of Cd in water system [32]. Dose-related bioaccumulation of lead was also observed in I. elegans from Donghu Lake, Jiangxi Province showed the indication function of $I$. elegans in lead-polluted water [33]. Cadmium-induced production of a metallothioneinlike protein in Chironomus riparius (Diptera) is found to be correlated with the reproduction and growth [34]. Heavy metals in sediments increase hsp70, a stress protein that alters lysosomal membrane stability in two species of caddisfly [35]. These results indicate that the possible use of these insect species as the adjuvant bioindicators for aquatic metal pollution, which may offer the useful biomonitoring data for the decisions of the high monetary investment in the management especially for freshwater.

\subsection{Bivalve mollusks}

Bivalve mollusks, as filter-feeding organisms, are known to accumulate metals that can produce deleterious effects on organisms. Professor Goldberg of the Scripps Institution of Oceanography has proposed a 'Mussel Watch' monitoring program to assess the spatial and temporal trends in chemical contamination in estuarine and coastal areas. A global scale-monitoring program based on the 'sentinel organism concept' has been outlined that is capable of detecting trends in concentrations of several marine contaminants. Mussels or other bivalves are commonly preferred for biomonitoring of aquatic metal pollution because of their advantages over the other organisms as explained by Tanabe and Subramanian [36]. Bivalve species including oyster, mussels and clams are enclosed as the biomonitors for the evaluation of heavy metals pollution in marine waters [37]. Several attributes that make mussels superior than other organisms for environmental monitoring include as follows: wide geographical distributing, abundant, sedentary, tolerant to environmental alterations, tolerant to various environmental contaminants, high bioconcentration factors of pollutants, very low-level metabolizing enzyme activities of organic contaminants, wide and stable populations, reasonably long-lived, reasonable size, sturdy enough to survive in laboratory and field studies in cages etc. Lots of bivalve mollusks have been adopted in the biomonitoring of metal pollution in aquatic ecosystem. Exemplary bivalve mollusks include mussel, oyster, clam etc. Bioaccumulation is the common used means in biomonitoring using this species. Alterations of enzyme activities like alkaline phosphatase are also reported due to heavy metal exposure. 
Bioaccumulation and distribution of heavy metals in bivalve mollusks are commonly studied and high tolerance to the stress of heavy metal exposure was exhibited in some of the species. For example, in situ cage experiment performed under tropical field conditions showed that the bioconcentration factors of two kinds of oysters (Crassastrea iredalei and $\mathrm{C}$. Belcheri) were $2.9 \times 10^{5}$ for $\mathrm{Zn}, 8.0-8.1 \times 10^{3}$ for $\mathrm{Cu}, 2.6-4.1 \times 10^{3}$ for $\mathrm{Cd}, 0.9-1.8 \times 10^{3}$ for $\mathrm{Pb}$ [38], indicating the high accumulation ability of heavy metal in oyster. The contents of $\mathrm{Cu}$ and $\mathrm{Zn}$ in the oysters were 1700 and 14,000 ppm from Tasmania, 1413 and 8629 ppm from Hong Kong [39]. High level of $\mathrm{Cu}(5000$ ppm) was also found in the green oyster in Siensan Area, Taiwan [40]. Positive relationship was also found between the levels of $\mathrm{Pb}, \mathrm{Cd}, \mathrm{Ni}$ and $\mathrm{Co}$ in Crassoarea corteziensis and in ambient marine system [41]. Yap et al. [42] suggested crystalline style the green-lipped mussel Perna viridis as an indicator of $\mathrm{Pb}$ bioavailability and contamination in the coastal waters. Laboratory simulative researches showed the biological (for example respiration), biochemical (for example enzyme activities) responses were induced by heavy metal residues ( $\mathrm{Cd}$ and $\mathrm{Cu}$ ) in the organisms [43]. Cd exposure to Corbicula fluminalis could obviously inhibit the activity of alkaline phosphatase [44].

In addition, most embryo and larva of aquatic invertebrate animals are pelagic. After metamorphosis, the mollusks live in a sedentary life, or they will die of being preyed. Larval metamorphosis thus plays key roles in the blossom of the population. Both the inner structural and functional alterations and the modal changes may occur during the metamorphosis process, which can be affected by exogenous disturbance, thus offering the obvious observable index [45]. Compared to $\mathrm{LC}_{50}$ test, larval metamorphosis brings a more sensitive process for the monitoring of the toxicity of the pollutants [46], which may be used for the risk assessment of environmental pollution. Metamorphosis of the chiton Ischnochiton hakodadgnsis has been reported for the evaluation of marine pollution. High sensitivity of larval chiton to the exposure of $\mathrm{Cu}^{2+}, \mathrm{Zn}^{2+}, \mathrm{Cd}^{2+}$, indicating its feasibility of the use as the standard monitoring approach of waste discharge and for the routine monitoring of marine water quality [47].

Interaction between different pollutants in bivalve mollusks and their habits of intermittent and filter feeding may also affect its indicating ability of aquatic pollution, however. In addition, most of bivalve mollusks live alongshore, which limits their use in biomonitoring of remote marine area.

\subsection{Gastropod}

Gastropods are a kind of mollusks similar to bivalve clams and oysters. The gastropods are polyphagia and mostly bottom dwellers. They can rise to the surface to get food by increasing buoyancy. They feed on egesta of fish etc. Gastropods have long been known to naturally accumulate metals to high concentrations. Simulative exposure test of mudsnail (Cipangopaludina cahayensis) showed it a suitable bioindicator for the toxicity and bioavailability of heavy metal. The bioavailability of various heavy metals could thus be concluded based on the levels in the mudsnail [48]. Different gastropod species can, however, exhibit different accumulative abilities for various metal compounds, which may offer various potential bioindicators for the biomonitoring of aquatic metal pollution [49].
Prosobranch gastropods exhibit all types of sexuality but in most individuals the sexes are separate and unchanged throughout life. Sexes are usually easy to identify based on either the presence or absence of a penis in diecious gastropods. However, the presence of a penis in a number of female Nucella lapillus from Plymouth in southwest England was first noticed in 1970s, which was generally related with the ambient organotin pollution [50]. The occurrence of imposex has been reported for approximate 100 species all over the world, which probably is the most sensitive response to TBT pollution. The detailed morphological alterations in gastropods exposed to organotin compounds have been subject to considerable researches. For Thais clavigera, the relative penis size index (RPSI) reached 10\% and the vas deferens sequence index (VDSI) was 2.8 when exposed to TBT solution of $3.7 \mathrm{ng} \mathrm{L}^{-1}$ for 8 months [51].

Some other characters such as the population, survive rate, individual weight can also be used to evaluate the toxicity of heavy metal in sediment. These findings may confirm the gastropod as a special bioindicator for aquatic metal pollution.

\subsection{Fish}

Fish has attracted much attention in the biomonitoring of water pollution due to its special biological characters such as relatively big body size, long life cycle, easy to raise etc. More importantly, fish species are at the top position in the aquatic food chain and may directly affect the health of humans, which makes it much of significance for the biomonitoring using fish. In the beginning of 1990s, lethal test of fish was proposed to evaluate marine pollution and was widely used as the main biomonitoring method. Behavior response of fish was also suggested to examine the toxicity of the pollutants [52]. The acute lethal rate, growth, reproduction, metabolism and fecundity of the fish can all be used for biomonitoring of aquatic pollution. Various fish have been reported in this respect such as zebrafish, medaka, the Chinese rare minnow, loach etc. As an example, acute and sublethal toxicity of cadmium on the juvenile loach showed good dose-related effects could be induced. The 24 and $48 \mathrm{~h} \mathrm{LC} 50$ were 1.22 and $0.85 \mathrm{mg} \mathrm{L}^{-1}$, respectively. The lowest observable effect concentration was $0.08 \mathrm{mgL}^{-1}$ and the highest unobservable effect concentration was $0.04 \mathrm{mgL}^{-1}$. The results indicated the Chinese loach might serve as the suitable bioindicator for heavy metal pollution [53]. A comprehensive review article described fish bioaccumulation and biomarkers in environmental risk assessment and a suite of fish biomarkers such as metallothioneins (MTs), hematological parameters, immunological parameters, reproductive and endocrine parameters, histological and morphological parameters were involved to assess exposure to or effects of environmental metal pollution on aquatic ecosystems [54]. Relative long experimental period and high cost, however, sometimes limit the use of fish species in biomonitoring procedures.

\subsection{Amphibian}

The amphibian has special amphibious biological characters such as breathing through the skin, thus high penetrability of the skin endow the amphibian with high sensitivity to 
the exposure of aquatic pollutants. Based on the poisoned symptom, it is possible to identify the pollutant species. Preliminary quantitative analysis of pollution levels can be also performed according to the poisoned degree or affected area in the amphibian. In addition, the tadpoles of some amphibian live in aquatic system. Water quality can thus pose great influence on the growth and development of tadpole. Morphological observation of tadpole may offer another appealing approach for the accurate evaluation of water quality. The main symptoms induced by aquatic pollution mainly include contractive body showing " $\mathrm{S}$ " shape, curled tail with atrophic tail muscle, wide open of mouth and nose, protuberant eye, skin with numbers of nubbles, falling of cutaneous pigment and transparent skin, swelling head and loss of body weight etc. Based on these phenomena, it is possible to evaluate the toxicity of pollutants such as heavy metal on the amphibian.

Acute toxicities of four heavy metals were studied using the tadpole of green toad (Bufo viridis) as test model. Wherein, $\mathrm{Ag}^{+}\left(>0.1 \mathrm{mgL}^{-1}\right)$ could induce " $\mathrm{S}$ " shaped body, curled tail, open mouth, protuberant eye, skin with numbers of nubbles, rankled skin and pigment loss. The $96 \mathrm{~h} \mathrm{LC} \mathrm{L}_{50}$ of the green hoptoad exposed to $\mathrm{Cr}^{2+}$ is $1.1 \mathrm{mgL}^{-1}$ and the exposed individuals show tenuous arched bodies, curled tail, blebs on the skin, reduce of cutaneous pigment. $\mathrm{Hg}^{2+}$ exposure (0.32-0.56 $\left.\mathrm{mg} \mathrm{L}^{-1}\right)$ can induce the swelling abdomen, light colored of the skin, swelling purtenance observable through the transparent abdomen in the adult green hoptoad, while swelling head, open nose, contractive abdomen could occur in the tadpole exposed to $1.00 \mathrm{mgL}^{-1}$ of $\mathrm{Hg}^{2+}$ [55]. Deformities and increased metabolic rate were found in the Xenopus laevis and Rana pipiens exposed to mercury [56]. Aluminium exposure induced body size reducing, swimming speed slowing, increased susceptibility in Hyla cinerea [57]. Diphenyltin exposure made Ambystoma barbouri growth and development delayed [58]. The laboratory findings may provide the possibility of field survey using amphibian as the test material.

\subsection{Others}

Other species marine mammals like seal, sea lion can also be used for the biomonitoring of marine pollution due to their strong bioaccumulation ability of aquatic pollutants. The feather of some seabirds was reported to monitor mercury levels in marine environment [59]. The high migration, however, limits their wide use in biomonitoring of pollution in the given areas.

\section{Classification of biomonitoring techniques}

In the biomonitoring of aquatic heavy metal, different methods or techniques can be adopted based on different aims and demands. For example, dynamics analysis in the polluted organisms [60], determination of the contents of heavy metal in the specific organisms [61-62], measurement of enzyme activities in the polluted bioindicators [63], histopathological observation [64] and analysis of biomarker contents like photosynthetic pigment in the algae [15]. All alterations in physiological function, species abundance, population, communities of the aquatic organisms may also correspond to the condition of water ecosystem. Each technique shows its special advantages and may be applied in various fields.

\subsection{Bioaccumulation}

Bioaccumulation is an important process through which chemicals can affect living organisms. An increase in the concentration of a chemical in a biological organism over time may occur compared to the chemical's concentration in the environment. Bioaccumulation occurs when an organism absorbs a toxic substance at a rate greater than that at which the substance is lost. Several process including uptake, storage and elimination are involved during bioaccumulation. Bioaccumulation results from a dynamic equilibrium between exposure from the outside environment and uptake, excretion, storage, and degradation within an organism. Understanding of the dynamic process of bioaccumulation is a critical consideration in the regulation of chemicals such as aquatic metals.

As exemplary, a simulative exposure experiment was carried out to test the suitability of Mya arenaria as a new sensitive biomonitor of butyltin pollution in the marine system based on its special high bioaccumulation ability for butyltin compounds as shown in Fig. 1 [65]. According to the first-order kinetic model [66], the kinetic parameters of the accumulation rate constant $\mathrm{Ku}$ and $\mathrm{BCF}$ were calculated. The parameter of $\mathrm{Ku}$ ranged between 0.54 and 2.97 for $M$. arenaria and from 0.062 to 0.30 for Mytilus edulis, respectively. The bioconcentration factor (BCF) ranged from 15538 to 91800 for M. arenaria and from 1813 to 9000 for M. edulis (control species), respectively, after 28 days exposure. During the subsequent depuration test, it was found that the depuration rate constant was in the range of 0.0074-0.0098 day ${ }^{-1}$ for M. arenaria and 0.019-0.0328 day ${ }^{-1}$ for $M$. edulis based on first-order kinetics [67]. The biological half-life of TBT elimination $\left(t_{1 / 2}\right)$ ranged from 71 to 94 days for $M$. arenaria and from 21 to 36 for M. edulis. The extremely high level of TBT in $M$. arenaria showed that it has stronger ability to accumulate or lower rate to metabolize this kind of environmental pollutants than other sampled species, which promised M. arenaria as a potential new biomonitor to indicate butyltin pollution in oceanic environment [68].

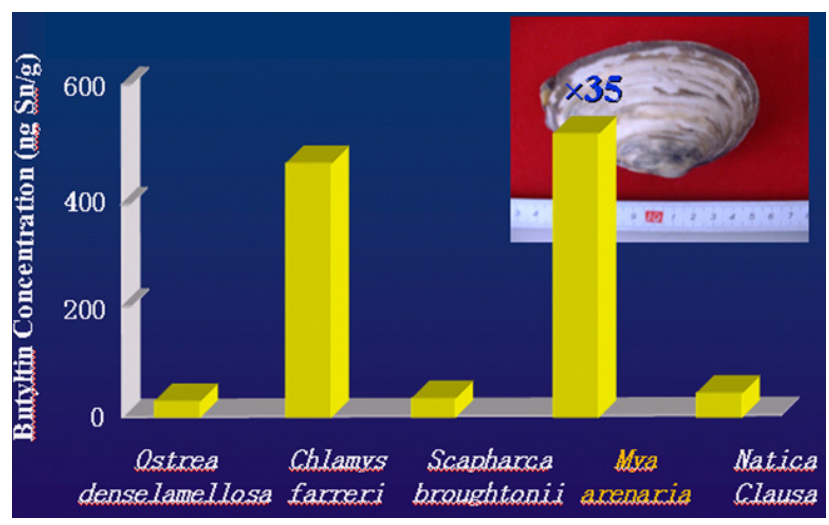

Fig. 1 - High bioaccumulation ability of Mya arenaria for butyltin pollution (source from Ref. [65]). 
Different levels of various pollutants can occur in the different organs in the same species. Studies on uptake and distribution of ${ }^{110 \mathrm{~m}} \mathrm{Ag}$ in oyster, Crassostrea gigas, from ambient water and food showed that the oyster could quickly and largely uptake waterborne $110 \mathrm{~m} A g$, the whole body concentration factor for $110 \mathrm{~m} A g$ reached as high as 2467 during 23 days of exposure. The concentration factors in the organs was in order of gill $(33,661)>$ mental $(23,119)>$ siphon $(21,818)>$ remainder part $(17,685)>$ adductor $(9915)>$ shell (189) [69]. Investigations on the levels of $\mathrm{Zn}, \mathrm{Cu}, \mathrm{Cd}, \mathrm{As}$ and $\mathrm{Pb}$ in the kidney, liver, gills and heart of African cat fish (Clarias gariepinus) from Nigeria Ogun River showed the trend of accumulation of the metals in the organs, which was as follows: heart, $\mathrm{Zn}>\mathrm{Cu}>\mathrm{Pb}>\mathrm{As}>\mathrm{Cd}$; gills, $\mathrm{Zn}>\mathrm{Cu}>\mathrm{Pb}>\mathrm{Cd}>\mathrm{As}$; kidney, $\mathrm{Zn}>\mathrm{Cu}>\mathrm{Pb}>\mathrm{As}>\mathrm{Cd}$; liver, $\mathrm{Zn}>\mathrm{Cu}>\mathrm{Pb}>\mathrm{As}>\mathrm{Cd}$. The order of metal concentrations in the organs was as follows: arsenite, kidney $>$ liver $>$ gills $>$ heart; zinc, gills $>$ liver $>$ kidney $>$ heart; lead, liver $>$ kidney $>$ gills $>$ heart; copper, kidney $>$ liver $>$ gills $>$ heart; cadmium, liver $>$ gills $>$ kidney $>$ heart [70].

The gills of mussels constitute major organs for metal accumulation [71]. Due to the fact that gills are the first organ of metal accumulation and larger surface area with mucus sheets in the organ, the mussel gill is a better accumulator of $\mathrm{Cd}, \mathrm{Pb}$ and $\mathrm{Zn}$ of ambient seawater than the remaining soft tissue, indicating it is a potential indicator of ambient levels of dissolved metals in the ambient seawater [72]. The highest $\mathrm{Hg}$ concentrations were also found in gills of $P$. viridis when compared to other tissues of mussels [73]. In other bivalves, Patel and Anthony [74] reported that the highest Cd concentration was found in the gills of Anadara granosa. Szefer et al. [75] found that the gills of cockle Cerastoderma glaucum contained highest concentrations of Co and $\mathrm{Ni}$ than other organs. The high bioconcentration factor in a metal free medium in mussel gills indicated that the gills were the sites of dominance for $\mathrm{Pb}$ and $\mathrm{Zn}$ assimilation in M. edulis [76]. George et al. [77] found Fe in the gills of $M$. edulis was localized in membrane bound vesicles that was formed by pinocytosis, of the epithelial cells on the gill surfaces.

The uptake, fate and effects of contaminants in organisms may be influenced by gender as it plays an important role in the genetics, physiology, morphology and behavior of organisms. Gender differences in metal levels in wildlife reviewed by Burger [78] existed in a range of aquatic bioindicators including invertebrates (e.g. Starfish, Asterias rubens), fish (e.g. Largemouth bass, Micropterus salmonides), reptiles (e.g. Water snakes, Nerodia sipedon), mammals (e.g. Dolphin, Stenella longirostris). The gender-related differences in metal accumulation in organisms may depend on several factors like metal species, accumulation tissues, season etc. For example, higher levels of copper existed in male shrimp, but females had higher levels of nickel in muscle, exoskeleton and muscle [79]. Significant gender-related differences in lead in muscle and skin of the moggel (Labeo umbratus) emerged only during the month of May [80]. Information concerned with the effects of gender on metal levels is still spotty and inconsistent. There are overwhelming needs for the study of the gender-related differences in metal bioaccumulation in various groups of aquatic animals.
Some other factors may also affect bioaccumulation of heavy metal in various organisms. The metals accumulated in the soft tissue of marine mussels can be affected by biotic factors including age, body size, nutrition, and reproductive status and also by environmental factors such as temperature and salinity [81] apart from pollution in the coastal waters. $\mathrm{Pb}$ and $\mathrm{Mn}$ contents in the mangrove oyster (C. corteziensis) were closely related with gonadal maturation and showed seasonal variation [82]. The measurement of metals in total soft tissues can provide information on the extent of metal exposure to an organism and a time-integrated measure of metal bioavailability [83]. The shells of the ocean quahog, as the indicators for heavy metal accumulation, are more suitable for reflecting historical contamination events than the soft body tissue [84]. Parameters that induce changes of the level of bioaccumulation of metal in mosses are environmental $\mathrm{pH}$, temperature, light, season, external metal concentration, competition between metals, mineral and organic suspended matter, current velocity and biological physiological state and variability between species [85]. Many factors may affect the bioavailability of metals to aquatic plants, such as ambient metal concentration, $\mathrm{pH}$ of soil or water, concentration of ligands, competition with other metals for binding sites, and mode of exposure. Water acidification affected plant concentrations of some metals and was especially important in the submerged pondweed [86].

\subsection{Biochemical alterations}

With the development of biological techniques, researches on the interaction between the pollutants and biological macromolecular such as protein, enzyme and nucleic acid may indicate the action mechanism of the pollutants. Precaution can thus be sensitively made at various levels. Many biomarkers have currently been developed such as metallothionein, oxidative stress, cytotoxicological responses such as genotoxicity, lysosomal alterations, immunocompetence and gencholinesterase activities etc. Some special protein can be purified to serve as biomarker for metal exposure as well. Suitable selection of biochemical biomarkers should be made based on specific conditions such as target pollutants, tested organisms, investigated areas etc.

MTs are a kind of soluble metal-binding proteins with low molecular weight. It exists in most eukaryotes where its primary role is the regulation of homeostasis of the essential metals copper and zinc. MTs have an additional protective role through their binding of toxic metals such as cadmium and mercury. Depending on the full understanding of its function and on the possibility of measuring its concentration in tissues, MT may be regarded as an early sign of alarm in the initial stage of contamination due to heavy metals. Increased expression of MT in response to harmful levels of these metals has been demonstrated for several aquatic species such as gastropods, insect, crustaceans, mussels, fishes etc. A high responsiveness was found in $\mathrm{MT}$ induction by cadmium in two crustaceans and a clear relationship between cadmium concentration in water and MT levels in tissues existed [87]. MT levels in the whelk T. clavigera from 11 sites in the coastal waters of Hong Kong were significantly correlated with Cd body concentrations and a clear relationship between the dis- 
solved Cd exposure and the resultant MT levels in the animals existed, indicating the credibility of MT as a biomarker for the evaluation of some related metal exposure [88]. Simultaneous study of MT contents and lysosomal membrane stability (LMS) in Mytilus galloprovincialis (L.) showed that MT contents were significantly less and LMS values were significantly greater in mussels collected from the reference station compared to those from heavy metal ( $\mathrm{Cd}, \mathrm{Pb}, \mathrm{Cu}$ and $\mathrm{Zn}$ ) polluted sites in the Gulf of Thermaikos [89], showing the feasibility of actual use of MT in the assessment of environmental pollution. Metallothionein mRNA was also reported to be implicated for biomonitoring. Quantitation of MT mRNA from the New Zealand common bully (Gobiomorphus cotidianus) could indicate the expression of MT in the liver tissue due to copper exposure for $48 \mathrm{~h}$. In addition, the heptic MT mRNA levels do not correlate with fish age, sex or sampling location, which avoids other factors' disturbance during heavy metal biomonitoring process. A comparison of two populations of common bullies from a polluted and a control site showed a 2-fold higher mean MT mRNA levels in fish from the polluted site, proving the implication for using MT mRNA as biomonitoring tool [90].

Chlorophyll a fluorescence, as a potential valuable ecotoxicological endpoint, could be used with a range of aquatic phototrophs. Chlorophyll a fluorescence-based ecotoxicological bioassays have been applied in the assessment of aquatic pollution including heavy metals. The main advantages are that it is rapid, non-invasive and non-destructive, while the major weakness is the lack of clear ecological relevance. Future research in aquatic chlorophyll a fluorescence ecotoxicology may focus on standardization of test protocols and statistical techniques [91].

Biomarkers indicating oxidative stress in the various organisms are proposed for the biomonitoring of aquatic metal pollution. The activities of superoxide dismutase (SOD), catalase (CAT), glutathione S-transferase (GST), glutathione (GSH) concentration and malondialdehyde (MDA) formation were reported to investigate the oxidative stress in African cat fish (C. gariepinus) from Nigeria Ogun River with metal pollution ( $\mathrm{Zn}, \mathrm{Cu}, \mathrm{Cd}, \mathrm{As}$ and $\mathrm{Pb}$ ). The results demonstrated that alterations in antioxidant enzymes, glutathione system and lipid peroxidation reflected the presence of heavy metal in the corresponding tissues, therefore confirming a rational use of biomarker of oxidative stress in biomonitoring of aquatic metal pollution [70]. Antioxidant and biotransformation enzymes in Myriophyllum quitense were reported as biomarkers of heavy metal exposure in Auquia River basin. M. quitense reacted to the pollution stress increasing the activity of GST, glutathione reductase and peroxidase. Elevated enzyme activities agreed to different pollution levels, especially inorganic nitrogen loads combined with elevated lead and aluminum concentrations, thus presenting $M$. quitense as a good biomonitor for assessment of water quality in the polluted aquatic ecosystem [92]. Biochemical stress of glutathione (GSH) levels in aquatic moss Fontinalis species showed alterations due to $\mathrm{Cd}^{2+}$ exposure over 10-day period [93]. Test of GST activity in two marine gastropods (Monodonta lineate and N. lapillus) exposed to copper and cadmium showed a significant reduction of $N$. lapillus GST after copper exposure but had no effect on $M$. lineate GST, indicating the selection of biochemical biomarkers should consider of the experimental species and tested pollutants [94].

Cellular biomarker including genotoxicity, lysosomal alterations, immunological responses and other protein or enzyme index, can also be used for monitoring estuarine environments. Genotoxic effects are evaluated as strand breaks by single cell gel electrophoresis (or Comet assay) and as chromosomal alterations by the micronucleus test in gill cells. Lysosomal alterations are assessed by the neutral red retention time (in haemocytes), lipofuscin accumulation, ultrastructure, size and number (in digestive cells). The phagocytic activity is used to evaluate the immunocompetence. Micronucleus frequency was found correlated with $\mathrm{Hg}$ concentration in M. galloprovincialis [95]. A general genotoxicity and lysosomal alterations were found in the Mediterranean mussel (M. galloprovincialis) from the River Cecina, accompanied by an elevation of tissue metal levels. Those based on DNA and lysosomal membrane integrity exhibited early biomarkers as they were induced at similar degree in native and transplanted mussels, while the alterations of micronuclei frequency, lipofuscin accumulation and mean lysosomal diameter resulted from cumulative pollution events [96]. Based on genetic variation, the correlation between a particular metal and the bands resulting from the use of a specific RAPD primer on P. viridis was reported as biomonitoring tool of heavy metal pollution [97]. A dose and time response both in phagocytic activity of haemocytes and lysosomal structural in the Asian clam (Corbicula fluminea) exposed to $10 \mu \mathrm{gL}^{-1}$ of cadmium demonstrated their use as biomarkers in freshwater biomonitoring [98]. The enzymes cholinesterases (ChEs) showing properties of both typical acetylcholinesterase and pseudocholinesterase in foot muscle of $\mathrm{M}$. lineate and $\mathrm{N}$. lapillus were increased by cadmium in vivo exposure and inhibited by copper in vitro exposure [94]. Some new biomarkers are now being explored for feasibility of its practical use. A polypeptide of $22 \mathrm{kDa}$ of molecular weight (LF22) was induced in Limnoperna fortunei exposed to sublethal levels of Cd (II), Cu (II) and $\mathrm{Hg}$ (II). LF22 triples its concentration in presence of Cd (II), indicating it a useful biomarker of heavy metal exposure [99]. High sensitivity and high speciality of these biomarkers responding to the aquatic metal pollution can exhibit the deleterious effects and the potential toxic mechanisms as well.

\subsection{Morphological and behavior observation}

Morphological and behavior observations provide the most direct effects of toxicant on the organisms, which can be commonly noticed, thus being an interesting topic of the related fields. In the biomonitoring of metal pollution in aquatic ecosystem, many techniques based on morphological observation have been developed using various organisms. Some of them are standardized as the criterions for the evaluation of individual or combined toxicities and for the risk assessment of environmental pollution.

\subsubsection{Morphological observation-imposex as a typical example}

Imposex is a typical phenomena induced by organotin compounds in prosobranch gastropods. Fig. 2 shows the exemplary masculinization phenomena found in Rapana venosa Valen- 

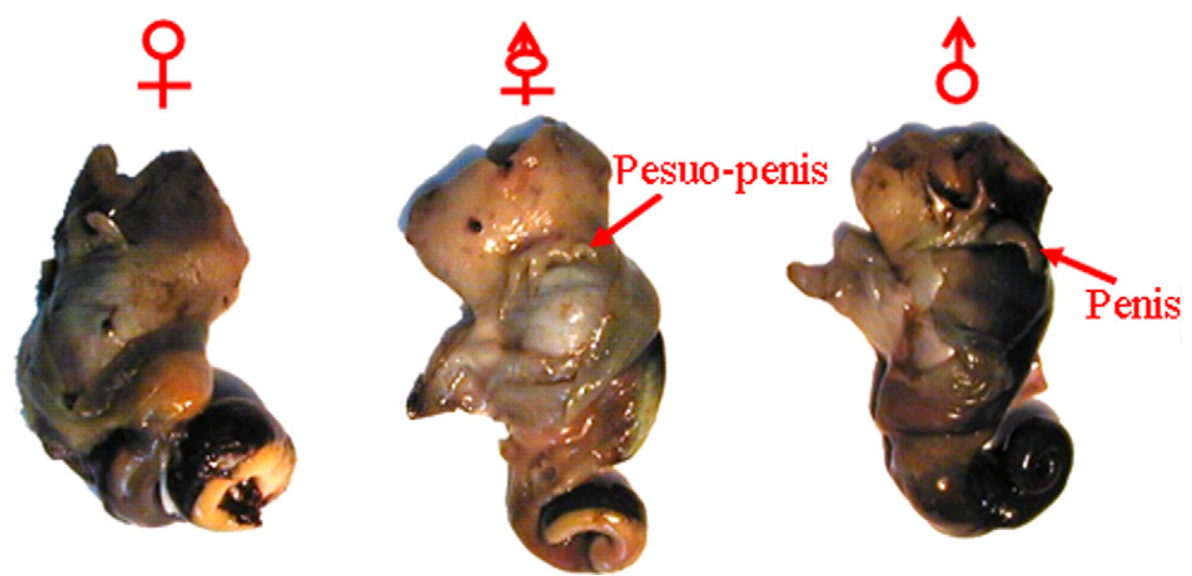

Fig. 2 - The masculinization phenomena found in Rapana venosa Valenciennes (source from Ref. [100]).

ciennes [100]. The masculinization phenomena may include imposex and intersex. The gradual and concentrationdependent increase of masculinization intensities in females can result in female sterility. In imposex-affected species, the entire female genital system is conserved but superimposed by male organs such as penis and/or vas deferens. While in intersex-affected species (such as Littorina Littorea), the female genital organs are developed toward a male morphological structure in lower intersex and then supplanted by the corresponding male formation, a prostate gland. The organ level phenomena can be measured and developed to monitor organotin pollution in the field. The incidence of imposex (IOI), sex ration (SR), relative penis size index, and vas deferens sequence index can be used for the imposex degree of the species. VDSI $>1$ indicates that some females are sterile and that the population has been affected [101]. The intersex index (ISI), as another parameter, indicates the reproductive capability of females in the given population. If ISI $>$ b2 in Littorina L., most females will have been sterilized [102]. Laboratory simulative experiments and field investigations show a good positive relationship existing between degrees of imposex and ambient TBT exposure levels [101,103]. These indexes, such as VDSI and ISI thus provide very good estimates of the reproductive capability of females in analyzed populations and have been widely used in surveys all over the world.

The phenomenon of imposex in prosobranch gastropods has received much attention in Asia. Lots of investigations have been performed in many countries such as Korean, Japan, Singapore, India, Malaysia and Indonesia. Several species are used as biomarkers and different indices are adopted even in the same species. For example, imposex in Babylonia formosae habei indicated organotin compound pollution in coastal water [104]. A preliminary investigation on imposex in southeast China showed imposex occurred at least in five snails. The frequency of imposex in T. clavigera reached $100 \%$ in Haikou, Beihai, Shenzhen, Huizhou, Shantou and Zhanjiang harbor, more than $90 \%$ in Xiamen harbor. Most individual T. clavigera in Haikou, Zhanjiang, Shenzhen and Huizhou were sterilized [105]. The results obviously indicate the feasibility of the biomonitoring technique based on imposex investigation in the assessment of organotin contamination caused by frequent marine traffic.
Other histopathological techniques and ultrastructural observations based on the optic microscope and the electric microscope may be involved in this aspect as well. As the non-specific approaches, they may effectively provide the information on the target tissues, cells and organelles in the organisms exposed to the chemicals, which helps to understand the potential toxicological mechanisms. For example, tributyltin exposure could induce cellular pathological alterations including vacuoles with increasing number and size, swelling of mitochondria, abnormal nuclei and decreases of rough endoplasmic reticulum cisternaes in the liver of the Chinese rare minnow (Gobiocypris rarus) [106]. Histopathological changes, such as oedema, vacuolization, pyknotic nucleus, telangiectasis and degenerative sperm were found in the liver, gill and gonad slices from medaka (Oryzias latipes) exposed to methylmercury [107]. The interaction between mercury and selenium was debated previously [108-111]. The histopathological observations helped to find that the interaction between $\mathrm{MeHg}$ and selenium at molar ration of 1:1 offered a limited protection against of both $\mathrm{MMC}$ and $\mathrm{Na}_{2} \mathrm{SeO}_{3}$ to medaka [112]. Accordingly, histopathological techniques can be obviously used to evaluate the toxicological effects of both individual pollutant and the complex chemicals.

\subsubsection{Behavior observation}

Acute lethal assay is the most common method for the toxicity evaluation of chemicals including metal compounds. Lots of organisms may be involved from zooplankton to fish. Many of them have been standardized as the routine tests. The index of $12,24,96 \mathrm{~h} \mathrm{LC}_{50}$ etc. have been used for the toxicity classification of the chemicals. The results of lethality can contribute to the perfect references for the accurate selection of the sublethal levels of pollutants for simulative exposure experiments and also provide the useful information on the right comparative assessment of environmental pollution. The $\mathrm{LC}_{50}$ values of various metallic compounds to different aquatic organisms are available in PAN Pesticides Database [113], showing the aquatic toxicity.

Other sublethal toxic effects have been proposed as the biomonitoring approaches for the more sensitive evaluation of chemical exposure compared to lethality. The toxicity endpoints include avoidance, feeding depression, valve closure 
behavior etc. The parameters such as $\mathrm{EC}_{50}$, LOEC etc. are used in this aspect.

If avoidance (sensu evasion, displacement) of contaminants occurs in real situations, then bioassays involving forced exposure severely underestimate pernicious effects of contamination. The study on the avoidance of copper contamination by field populations of Daphnia longispina showed significant avoidance to copper when exposed to a gradient from 3 to $87 \mu \mathrm{gL}^{-1}$. An intense association was observed between other endpoints and avoidance, furthermore, avoidance was much more sensitive than lethality [114]. As a complementary tool, avoidance assays is recommended for ecological risk assessments and effluent biomonitoring because such assays can provide cost-effective and ecologically relevant information. The chronic feeding assays appear to be a rapid, cheap and effective toll to be used in biomonitoring studies. An increase in cadmium and zinc at sublethal levels resulted in significant reductions of the feeding rate of two freshwater crustaceans: Atyaephyra desmarestii (Decapoda) and Echinogammarus meridionalis (Amphipoda). The LOECs of zinc were $1.29 \mathrm{mgL}^{-1}$ for $A$. desmarestii and $0.4 \mathrm{mgL}^{-1}$ for $E$. meridionalis. The LOEC of cadmium was $6.53 \mu \mathrm{gL}^{-1}$ for both species [115]. Based on the closure daily rhythm and the corresponding dose-response profiles, the valve closure behavior in the clam such as $C$. fluminea can be also used as a toxicity endpoint for the biomonitoring of the aquatic heavy metals [116].

For aquatic plants, parameters such as foliar injury, chlorophyll content and phytomass may indicate the harmful effects after heavy metal exposure. Perceptible effects with increasing exposure to the metal could be obtained based on these parameters when three aquatic plants (Hydrilla verticillata Presl, Pistia stratiotes L. and Salvinia molesta D.S. Mitchell) were treated with different concentrations of mercury. A positive relationship between leaf injury index (LII) and doses of the metal was obtained in the case of floating plants [117]. Simple bioassay based on these parameters is feasible in biomonitoring and toxicity studies.

\subsection{Population- and community-level approaches}

Population-level (density, size distribution) and communitylevel (species richness metrics, multivariate analysis of community composition) responses of the aquatic organisms to metal pollution in aquatic ecosystem are much of significance for the evaluation of the ecological balance induced by water qualities in the studied area. Single or various populations may be involved for different aims.

The biomonitoring of PFU protozoan communities (abbreviated as PFU method) comprises of collecting protozoan communities using a foam block, analyzing the population configuration and functional parameters for the corresponding water assessment. PFU protozoan communities play the substantial role and show the clear advantages in biomonitoring with relation to water quality. The benchmark for the highest allowable level of the pollutants in water system can be made based on the data obtained by PFU method. PFU method has been established as a national standard method for the biomonitoring of water quality in China [118]. It can be applied to the field monitoring of the pollution in freshwater including lakes, reservoirs, ponds, rivers, streams and brooks, the test of toxicants in wastewater from industrial discharge, urban sewage, and the risk assessment of integrated water qualities. Lots of researches showed that heavy metal pollution could disturb the configuration and function of protozoan $[119,120]$. PFU protozoan communities were reported to apply to monitor the effectiveness of constructed wetland dominated by Typha latifolia in treating wastewater from a $\mathrm{Pb} / \mathrm{Zn}$ mine and physico-chemical properties of wastewater were also analyzed for comparison. The results showed that the species richness individual abundance, PFU colonization rate and especially bio-diversity index were useful for indicating the water quality. Both the PFU method and physico-chemical analysis indicated the mine wastewater could be affectively purified by the constructed wetland [121].

In situ microcosm experiments can be conducted to assess population- and community-level responses to aquatic heavy metal pollution. The investigation of macroinvertebrates in the Arkansas River, a mining-polluted stream in Colorado, USA showed significant mortality at metal-contaminated sites during summer when mayfly populations were dominated by small, early instars. The concentration-response relationships between heavy metals and R. hageni density, species richness, mayfly richness and EPT were established, wherein different sensitivities might exist due to the phenology and developmental stage influencing responses of some aquatic macroinvertebrates to metals. Timing bioassessments to coincide with the presence of these sensitive life stages can improve the ability to detect subtle contaminant effects [122]. The taxa richness for aquatic benthic insect community can be used to indicate the impact of acid mine drainage in a tropical Asia stream [123]. The population structure of bivalve mollusks can indicate aquatic metal exposure. Higher benthic organism density of the ocean quahog Arctica islandica L. (Mollusca, Bivalvia) was found in the less-contaminated reference in comparison to the dumping site and the absence of juvenile and adult individuals in the dumping sites with copper and lead pollution indicated the ecological environment didn't completely regenerated due to dumping event in the late 1950s to early 1960s [83]. The populations of some gastropods are commonly used for the biomonitoring of organotin pollution due to their imposex response to tributyltin compound [124]. Field studies showed the water quality of Pearl River, Guangzhou could be effectively evaluated by counting C. fluminea population [125].

Alterations in population- and community-level may indicate the disturbance the normal balance in the studied ecosystem, thus causing serious aftereffects, which make it much of importance to carry out the biomonitoring program at this level. Lots of efforts should be devoted for this purpose due to the anfractuosity of such researches.

\subsection{Modeling in biomonitoring}

Based on the experimental results or published data, it is possible to develop mechanistic models for the understanding the various biological alterations under the stress of environmental pollution, such as modeling $\mathrm{Na}$ transport-valve closure behavior, Cu-BLM-Corbicula model, extra and intracellular uptake and discharge of heavy metal etc. Using modeling 
analysis, prediction of chemical toxicity and the potential mechanisms for the metabolism and toxicity of the pollutants can be performed.

For example, a mechanistic model to describe a "fluxbiological response" approach based on biotic ligand model (BLM) and Michaelis-Menten (M-M) kinetics to allow the linkage between valve closure behavior and sodium transport mechanism in freshwater clam C. fluminea in response to waterborne copper was developed. The $\mathrm{M}-\mathrm{M}$ maximum $\mathrm{Cu}$ internalization flux in C. fluminea, a half-saturation affinity constant, dynamics of $\mathrm{Na}$ uptake and valve closure daily rhythm driven by external $\mathrm{Cu}$ could be predicted based on this "Na transport-valve closure behavior" approach, thus providing the basis of a future design of biomonitoring tool [116]. The proposed Cu-BLM-Corbicula model showed that free ionic form of waterborne $\mathrm{Cu}$ binding specifically to clam gill impaired normal valve closure behavior. The site-specific $\mathrm{EC}_{50}$ and valve closure behavior at any integrated time could be well predicted, indicating $\mathrm{Cu}$-BLM-Corbicula model can potentially offer a rapid and cost-effective method to perform ecological risk assessment [126]. Compared to the free ion activity model and the biotic ligand model, the subcellular partitioning model (SPM) considers more about the complexity of internal metal subcellular fractionation, which may significantly affect metal toxicity in aquatic organisms and subsequent trophic transfer of metals to consumers [127]. The uptake and discharge behavior of heavy metals in the extra and intracellular compartments fitted perfectly a Michaelis-Menten model and an inverse Michaelis-Menten model [128]. A two-compartment model was proposed for the modeling cadmium exchange by an aquatic moss (Fontinalis dalecarlica) and the closely fitted prediction results augured well for the wider use of this model for other moss species and metals [129].

The modeling approach thus offers another high effective choice for biomonitoring with low cost, which may be widely used for the risk assessment of metal pollution in aquatic ecosystem.

\section{Application}

\subsection{Evaluation of metal pollution in aquatic ecosystem}

The most important application of biomonitoring is for the evaluation of metal pollution in aquatic ecosystem including harbors, continental waters, heavy metal mining areas etc. It may offer the effective precaution system based on these biomonitoring data. The performance of the wastewater treatment can be evaluated as well. Numbers of researches have been reported in this aspect using a variety of biomonitoring techniques.

For example, the freshwater river crab, Potamonautes warreni, as a bioaccumulative indicator was used to indicate iron and manganese pollution in two aquatic systems (Germiston Lake and Potchefstroom Dam) [130]. Based on the analysis of the lead, zinc and cadmium bioaccumulation in plant biomass (detritus, periphyton and filamentous algae), invertebrates (snails, crayfish and riffle benthos) and two taxa of fish, metal pollution was evaluated in streams draining lead-mining and non-mining areas, southeast Missouri, USA.
The results demonstrated that long-term $\mathrm{Pb}$ mining activity in southeast Missouri resulted in significantly elevated concentrations of $\mathrm{Pb}, \mathrm{Cd}$ and $\mathrm{Zn}$ in biota of receiving streams [131]. Study on residual quantity of $\mathrm{Hg}, \mathrm{Cd}, \mathrm{Pb}$ and $\mathrm{As}$ in Scapharca subcrenata along coat of Bohai and Yellow sea indicated the pollution with the investigated area by four metals decreased during 1990-1997 [132]. Investigation on butyltin compounds in mollusks from Chinese Bohai coastal waters indicated ongoing usage of TBT-based antifouling agents leading to aquatic organotin pollution in China, and also showed a potential danger for the health of the local people who cared for these polluted seafoods [133].

Compared to the results obtained from the water and sediment samples, the biomonitoring data may provide the more integrated information on the long-term or current aquatic pollution status and the corresponding potential effects on the non-target organisms even on human beings as well.

\subsection{Bioremediation}

Biomonitoring using some special high metal accumulative species especially for aquatic plants may offer the approach for the establishment of the bioremediation plan to restore water quality. Phytoremediation technologies use plants to reduce, remove, degrade, or immobilize environmental toxins [134]. As reviewed by Prasad and Freitas [135], significant progress in phytoremediation has been made with metals and radionuclides. The phytoremediation process for aquatic pollution involves rising of plants hydroponically and transplanting them into metal-polluted waters where plants absorb and concentrate the metals in their roots and shoots. As they become saturated with the metal contaminants, roots or whole plants are harvested for disposal.

Among the microorganisms, algae are of predominant interest for the ecological engineer because of their ability to sequester uranium and because some algae can live under many extreme environments, often in abundance. Algae grow in a wide spectrum of water qualities, from alkaline environments to acidic mine drainage wastewaters. If they could be induced to grow in wastewaters, they would provide a simple, long-term means to remove uranium and other radionuclides from uranium mining effluents [136]. Aquatic plants have been identified as a potentially useful group for accumulating and bioconcentrating heavy metals. High metal removing potential of some aquatic plants could be a useful phytoremediation technology by harvesting submerged and floating biomass inhabiting littoral zone of Lake Nainital [16]. The duckweed (Lemna minor) was corroborated to be a suitable candidate for the phytoremediation of low-level copper and cadmium contaminated water body [137]. Tolerant response of aquatic macrophyte, $H$. verticillata (L.f.) Royle to moderate copper exposures and high accumulation potential warrants their suitability for remediation of moderately copper polluted water bodies [138]. Hyperaccumulation of various metals by different plant species with some of these metals being partitioned to the shoots, roots is much of importance for environmental implications. The macroinvertebrate assemblage and aquatic habitat were assessed with the objective of monitoring remediation efforts based on the measurement of concentrations of $\mathrm{As}, \mathrm{Cd}, \mathrm{Cu}, \mathrm{Pb}$, and $\mathrm{Zn}$ in biofilm 
and macroinvertebrates from the Boulder River Watershed, MT, USA [139]. Phytoremediation may also play key roles in preventing metal mine waste from further environmental degradation, as reviewed by Das and Maiti. [134].

Compared to other skills for the clean up of aquatic metal pollution, bioremedation techniques based on biomonitoring offered an appealing approach due to the advantages as follows: easy to use, effective-fast cleanup vs. natural attenuation, environmentally safe and natural treatment, easy to apply and no protective clothing required, low cost efficient and long-term solutions for balanced ecosystem.

\subsection{Toxicology prediction}

The benefit of a toxicological database based on biomonitoring information is to establish the biological models for the evaluation and prediction of potential effects of chemicals. Various of models have been concerned for the different aims of toxicity prediction in given conditions.

Bioaccumulation of As, Co, Cr and Mn in Hyalella azteca was useful for predicting chronic mortality based on a saturationbased mortality model relative to total-body or water metal concentration [140]. The acute toxicity of the metal mixture to $D$. magna could be well predicted when the modified $L_{50}$ values was employed as the basis of hardness in the toxic unit (TU) calculation, which was useful in the prediction of acid mine drainage toxicity [141]. Biotic ligand models (BLMs) have been developed for various metals (e.g. $\mathrm{Cu}, \mathrm{Ag}, \mathrm{Zn}$ ) and different aquatic species. Predicting acute copper toxicity to valve closure behavior in the freshwater clam $C$. fluminea with derived mechanistic-based Cu-BLM-Corbicula model can be used to assist in developing technically defensible sitespecific water quality criteria [126]. The prediction of cadmium toxicity to small aquatic organisms could be performed by the subcellular partitioning model [127]. Cd concentrations in the gill cytosolic HMW pool of the individual molluscs were the biomarker response that was most frequently and most strongly correlated with the population variables, which indicated subcellular metal distribution contributed to the prediction of ecologically significant effects (i.e. at the population or community levels) [142].

However, lack of standardization of toxicology databases hinders the accurate toxicological prediction and its effective practical use to some extent.

\subsection{Toxicological mechanism}

Studies based on the biomonitoring of the combined biochemical responses to aquatic metal exposure in the bioindicators and the ultrastructural observations may help the better understanding of the potential toxicological mechanism. Biomarkers of oxidative stress, genotoxicity etc. explain the toxicological effects at cellular different levels. Simulative exposure tests are usually involved for this intention. For example, oxidative stress responses in gill and kidney were investigated in European eel (Anguilla anguilla L.) exposed to chromium and PAHs, and measured as lipid peroxidation (LPO), glutathione peroxidase (GPX), catalase and glutathione S-transferase activity, and reduced glutathione (GSH) concentration, whereas genotoxicity was measured as DNA strand breakage. The results showed the alterations in antioxidant levels and the loss of DNA integrity, contributing to a better knowledge about oxidative stress and mechanisms of genotoxicity induced by $\mathrm{Cr}$ and PAHs in fish [143]. Preliminary screening of the potential toxicological mechanisms can be performed based on biomonitoring, however, much more further specialized researches are still needed in view of this aspect.

\section{Further prospects}

Biomonitoring provides the direct the evidences of alterations occurred in the ecosystem due to environmental pollution. Integrated information on the water quality can be reflected based on the biomonitoring of aquatic metal pollution, which offers the potential effects and actual toxicities. Great progress has been achieved due to the efforts of previous researches in the biomonitoring of metal pollution in aquatic system. Numbers of bioindicators or biomonitors including various species are proposed based on their special behavior responses to metal exposure such as high bioaccumulative ability, which also offers appealing approaches for the bioremediation of aquatic pollution. Lots of biomarkers at the cellular levels are developed due to the sensitive responses of the organisms, which may provide the precaution of toxic effects induced by current pollution, and also explain the potential toxicological mechanisms. Various models are established for the well prediction of toxicities of some metal pollutants to the organisms. Nevertheless, based on biomonitoring of metal pollution in aquatic ecosystem, much is to be done in developing technically defensible site-specific water quality criteria, performing ecological risk assessment, promoting more focused and efficient uses of resources in the regulation and control of metals and the protection of the aquatic ecosystems. Following aspects are to be strived in view of biomonitoring of metal pollution in aquatic ecosystem.

1. To exert the precursory action in the biomonitoring of wastewater discharge. Due to the prominent advantages, the scientific data based on biomonitoring should screen the priority of pollution source necessary for the further physico-chemical analyses and the corresponding controlling steps.

2. To establish the precaution system for aquatic metal pollution. With the rapid development of industry, lots of new metallic compounds with little knowledge of their toxicity may enter into the water bodies, causing the uncertain harmful effects on non-target aquatic organisms and human beings. The biomonitoring network may provide important information on the aquatic pollution level, bioaccumulative factor and potential ecological effects, thus exhibiting the precaution function for occurrence of the dangerous poisoning accidents.

3. To develop the comprehensive monitoring approaches based on the combination of biomonitoring and physicochemical analyses. The physico-chemical analyze can find the detailed metal species and their pollution levels in the water, sediments, while biomonitoring study may offer bioaccumulation level, integrated toxicological effects. The 
combination of two approaches may greatly reinforce the comprehensive assessment of the metal pollution in aquatic ecosystem.

4. To enact the legislative standards for more biomonitoring approaches. Lake of the accordant criteria of biomonitoring limits its wide use and the possible comparison in the actual evaluation of aquatic metal pollution. Urgent measures should be taken to establish defensible site-specific water quality criteria and biomonitoring standards for the regulation and control of metals and the protection of the aquatic ecosystem.

\section{Acknowledgements}

This work was jointly supported by the State High Tech Development (2006AA06Z424), National Natural Science Foundation of China $(40503014,20621703)$, the Chinese Academy of Sciences (KZCX2-YW-420-21) and Beijing Nova Programme (2004A51).

\section{REFERENCES}

[1] L. Jin, Environ. Bionomy, first ed., High Education Press, Beijing, 1992.

[2] X.X. Chang, C.H. Wen, H.J. Wang, Yunnan Environ. Sci. 19 (2000) 59.

[3] L. Huang, W. Li, Res. Environ. Sci. 15 (2002) 1.

[4] L.N. Liang, J.T. Hu, D.Y. Chen, Q.F. Zhou, B. He, G.B. Jiang, Bull. Environ. Contam. Toxicol. 72 (2004) 937.

[5] J.L. Xu, J.R. Yang, Heavy Metals in Terrestrial Ecosystem, China Environmental Science Press, Beijing, 1996.

[6] S.D. Wu, H.F. Zhao, The Analytical Methods in the Monitoring of Water and Wastewater, China Environmental Science Press, Beijing, 2006.

[7] P.G.C. Campbell, Environ. Chem. 3 (2006) 387.

[8] State Environmental Protection Administration (SEPA), Environ. Educ. 4 (2001) 46.

[9] J.N. Chang, J.G. Qu, Sichuan Environ. 24 (2005) 29.

[10] S.Y. Chen, Zhangzhou Professional Uni. Acta 3 (2002) 54

[11] Z.G. Zhang, Sci/Tech. Inf. Dev. Economy 14 (2004) 150.

[12] T. Yan, H.J. Lv, Mar. Environ. Sci. 8 (1989) 50.

[13] Y. Yang, Chin. J. Health Lab. Technol. 16 (2006) 1538.

[14] J. Burger, Environ. Bioindicators 1 (2006) 136.

[15] Y.T. Hao, J.H. Li, X. Pan, Y.X. Ma, X.F. Wang, J. Lake Sci. 13 (2001) 158

[16] M.B. Ali, R.D. Tripathi, U.N. Rai, A. Pal, S.P. Singh, Chemosphere 39 (1999) 2171.

[17] J.I.N. Kumar, H. Soni, R.N. Kumar, J. Limnol. 65 (2006) 9.

[18] I. Bruns, K. Friese, B. Markert, G.J. Krauss, Sci. Total Environ. 204 (1997) 161.

[19] M.Q. Xu, Z.J. Wang, Chin. J. Appl. Environ. Biol. 2 (1996) 169.

[20] C.M. Yue, Z.H. Ming, Microbiology 27 (2000) 215.

[21] M.Q. Xu, H. Cao, Acta Ecologica Sinica 24 (2007) 1540.

[22] M.M. Adema, Hydrobiologia 59 (1978) 125.

[23] L. De Meester, Ecology 74 (1993) 1467.

[24] L. Yuan, E.L. Michels, M. De, J. Environ. Sci. 15 (2003) 841.

[25] Y.G. Wu, Y. Xiong, C.X. Lin, J. Yunnan Agri. Univ. 21 (2006) 657.

[26] Y.G. Wu, J.G. Huang, L. Yuan, China Environ. Sci. 24 (2004) 336.

[27] Q. Liu, Enviro. Monitor. in China 16 (2000) 38.

[28] P.B. Key, E.F. Wirth, M.H. Fulton, Environ. Bioindicators. 1 (2006) 115
[29] C. Downs, J. Fauth, C. Woodley, Mar. Biotechnol. 3 (2001) 380.

[30] J. Ritterhoff, G.P. Zauke, Mar. Pollut. Bull. 34 (1997) 614.

[31] N. Bonada, N. Prat, V.H. Resh, B. Statzner, Annu. Rev. Entomol. 51 (2006) 495.

[32] F.Y. Han, Y.Y. Xi, Agro-Environ. Prot. 20 (2001) 229.

[33] F.Y. Han, Y.Y. Xi, H. Bi, Agro-Environ. Prot. 21 (2002) 169.

[34] P.L. Gillis, L.C. Diener, T.B. Reynoldson, D.G. Dixon, Environ. Toxicol. Chem. 21 (2002) 1836.

[35] I. Werner, K. Broeg, D. Cain, W. Wallace, M. Hornberger, Biomarkers of heavy metal effects in two species of caddisfly larvae from Clark Fork River, Montana: stress proteins (HSP70) and lysosomal membrane integrity, in: Presented at 20th Annual Meeting Society of Environmental Toxicology Chemistry, 1999.

[36] S. Tanabe, A. Subramanian, Biomarkers and Analytical Methods for the Analysis of POPs in Developing Countries, STAP/GEF and Ministry of Environment, Government of Japan (Sponsored) STAP Workshop on The Use of Bioindicators, 2003, p. 1.

[37] D.W. Boening, Environ. Monit. Assess. 55 (1999) 459.

[38] P.E. Lim, C.K. Lee, Z. Din, Sci. Total Environ. 216 (1998) 147.

[39] G.M. Ayling, Water Res. 8 (1974) 729.

[40] S. Lin, I.J. Hsieh, Mar. Pollut. Bull. 38 (1999) 960.

[41] F. Paez-Osuna, C. Marmolejo-Rivas, Bull. Environ. Contam. Toxicol. 45 (1990) 538.

[42] C.K. Yap, A. Ismail, W.H. Cheng, S.G. Tan, Ecotox. Environ. Safe. 63 (2006) 413.

[43] L.X. Zeng, G.Z. Chen, H.H. Wu, J. Agro-Environ. Sci. 26 (2007) 175.

[44] X.Q. Huang, Y.B. Long, J. Fujian Teachers Univ. 11 (1995) 74.

[45] R.J. Wu, X.L. Zhang, J.S. Zheng, M.Y. Zhu, J. Oceanography Huanghai Bohai Seas 20 (2002) 66.

[46] H.L. Phelp, K.A. Warnes, Environ. Toxicol. Chem. 44 (1990) 197.

[47] A.N. Tyurin, Russ. J. Mar. Ecol. 20 (1991) 56.

[48] M.X. Guo, Y.H. Lin, Environ. Exploit. 12 (1997) 8.

[49] L.N. Liang, B. He, G.B. Jiang, D.Y. Chen, Z.W. Yao, Sci. Total Environ. 324 (2004) 105.

[50] S.J.M. Blaber, Proc. Malai. Soc. Lond. 39 (1970) 231.

[51] T. Horiguchi, H. Shiraishi, M. Shimizu, M. Morita, Environ. Pollut. 95 (1997) 85.

[52] J.J. Carns, Water Res. 15 (1981) 941.

[53] X.Y. Jia, Environ. Pollut. Control. 23 (2001) 227.

[54] R. van der Oost, J. Beyer, N.P.E. Vermeulen, Environ. Toxicol. Pharm. 13 (2003) 57.

[55] A.M. Wang, J. Xinjiang Univ. 7 (1990) 60.

[56] K. Dumpert, E. Zietz, Ecol. Environ. Safe. 8 (1984) 55.

[57] R.E. Jung, C.H. Jagoe, Can. J. Zool. 73 (1995) 2171.

[58] S.G. Lynn, J.S. Rehage, A. Sih, B.D. Palmer, Society of Environmental Toxicology and Chemistry 21st Annual Meeting, Nashville, TN, November 12-16, 2000.

[59] T. Odsjö, A. Roos, A.G. Johnels, AMBIO J Human Environ. 33 (2004) 133.

[60] B. Inza, F. Ribeyre, A. Boudou, Aquat. Toxicol. 43 (1998) 273.

[61] B. Fraysse, J.P. Baudin, J.G. Laplace, C. Adam, A. Boudou, Environ. Pollut. 118 (2002) 297.

[62] H.A. Rodtti, N.S. Fisher, S.A.S. Wilhelmy, Environ. Sci. Technol. 34 (2000) 2817.

[63] D.R. Lai, Acta Oceanologica Sinica 5 (1983) 230.

[64] S.J. Teh, J.S.L. Clark, C.L. Brown, S.N. Luoma, D.E. Hinton, Biomark 4 (1999) 497.

[65] Q.F. Zhou, Z.Y. Li, G.B. Jiang, R.Q. Yang, Environ. Pollut. 125 (2003) 301.

[66] H. Yamada, K. Takayanagi, Water Res. 26 (1992) 1589.

[67] J.L. Gomez-Ariza, E. Morales, I. Giraldez, Mar. Environ. Res. 47 (1999) 399. 
[68] R.Q. Yang, Q.F. Zhou, G.B. Jiang, Chemosphere 63 (2006) 1.

[69] C.G. Zhong, S.H. Chen, Y.X. Li, R.W. Xie, Acta Agri. Nucleatae Sinica 17 (2003) 388.

[70] E.O. Farombi, O.A. Adelowo, Y.R. Ajimoko, Int. J. Environ. Res. Public Health 4 (2007) 158.

[71] C. Gundacker, Chemosphere 38 (1999) 3339.

[72] C.K. Yap, A. Ismail, A.R. Ismail, S.G. Tan, Wetland Sci. 4 (2006) 247.

[73] P.T. Lakshmanan, P.N.K. Nambisan, Bull. Environ. Contam. Toxicol. 43 (1989) 131.

[74] B. Patel, K. Anthony, Mar. Biol. 108 (1991) 457.

[75] P. Szefer, M. Wolowiez, A. Kusak, J.-M. Deslous-Paoli, W. Czarnowski, K. Frelek, M.-J. Belzunce, Arch. Environ. Contam. Toxicol. 36 (1999) 56.

[76] C.K. Yap, A. Ismail, S.G. Tan, H. Omar, Hydrobiologia 498 (2003) 151.

[77] S.G. George, B.J.S. Pirie, T.L. Coombs, J. Exp. Mar. Biol. Ecol. 23 (1976) 71.

[78] J. Burger, Environ. Res. 104 (2007) 153.

[79] F. Paez-Osuna, L. Tron-Mayen, Environ. Int. 22 (1996) 443.

[80] G. Nussey, J.H.J. van Vuren, H.H. du Preez, Water SA 26 (2000) 269.

[81] V.P. Chelomin, N.O. Lukjanova, E.A. Bobkova, Oceanic and Anthropogenic Controls of Life in the Pacific Ocean, Kluwer Academic Publisher, Netherlands, 1992, 287.

[82] M.G. Frias-Esperieueta, J.I. Osuna-Lopez, F. Paez-Osuna, Sci. Total Environ. 231 (1999) 115.

[83] D.J.H. Phillips, P.S. Rainbow, Biomonitoring of Trace Aquatic Contaminants, Elsevier Science, London, 1993, p. 371.

[84] G.A. Liehr, M.L. Zettler, T. Leipe, G. Witt, Mar. Biol. (Berlin) 147 (2005) 671.

[85] C. Ah-Peng, C.R. de Traubenberg, Cryptogamie Bryologie 25 (2004) 205.

[86] D.W. Sparling, T.P. Lowe, Water Air Soil Pollut. 108 (1998) 203.

[87] J. del Ramo, A. Torreblanca, M. Martínez, A. Pastor, J. Díaz-Mayans, Mar. Environ. Res. 39 (1995) 121.

[88] B. Graham, W.X. Wang, Mar. Ecol. Progress Series 277 (2004) 135.

[89] G.P. Domouhtsidou, S. Dailianis, M. Kaloyianni, V.K. Dimitriadis, Mar. Pollut. Bull. 48 (2004) 572.

[90] A.D. Laurie, New Zealand J. Mar. Freshwater Res. 38 (2004) 869.

[91] P.J. Ralph, R.A. Smith, C.M.O. Macinnis-Ng, C.R. Seery, Toxicol. Environ. Chem. 89 (2007) 589.

[92] J. Nimptsch, D.A. Wunderlin, A. Dollan, S. Pflugmacher, Chemosphere 61 (2005) 147.

[93] C. Bleuel, D. Wesenberg, K. Sutter, J. Miersch, B. Braha, F.A. Baerlocher, G.J.T. Krauss, Sci. Total Environ. 345 (2005) 13.

[94] I. Cunha, E. Mangas-Ramirez, L. Guilhermino, Comp. Biochem. Physiol. C Toxicol. Pharmacol. 145 (2007) 648.

[95] C. Bolognesi, G. Frenzilli, C. Lasagna, E. Perrone, P. Roggieri, Mutation Res. 552 (2004) 153.

[96] M. Nigro, A. Falleni, I.D. Barga, V. Scarcelli, P. Lucchesi, F. Regoli, G. Frenzilli, Aquat. Toxicol. 77 (2006) 339.

[97] C.K. Yap, B.H. Chua, C.H. The, S.G. Tan, A. Ismail, Genetika $43(2007) 668$.

[98] O. Champeau, M. Auffret, M.P. Cajaraville, A. Basseres, J.F. Narbone, Biomarkers 12 (2007) 173.

[99] M. Belaich, C. Oliver, M. Pilloff, P. Andres, Environ. Pollut. 144 (2006) 280

[100] G.B. Jiang, Q.F. Zhou, J.Y. Liu, Proceedings of The Third China-Japan Symposium on Water Environment 5 (2000) 41-51.

[101] P.E. Gibbs, G.W. Bryan, P.L. Pascoe, G.R. Burt, J. Mar. Biol. Ass. UK 67 (1987) 507.
[102] B. Bauer, P. Fioroni, L. Ide, S. Liebe, J. Oehlmann, E. Stroben, B. Watermann, Hydrobiologia 109 (1995) 15.

[103] W.J. Shim, S.H. Kahng, S.H. Hong, N.S. Kim, S.K. Kim, J.H. Shim, Mar. Environ. Res. 49 (2000) 435.

[104] H.H. Shi, C.J. Huang, Z. Lei, Ocean Technol. 22 (2003) 82.

[105] H.H. Shi, C.J. Huang, Acta Ecologica Sinica 21 (2001) 1711.

[106] Q.F. Zhou, G.B. Jiang, J.Y. Liu, Arch. Environ. Contam. Toxicol. 42 (2002) 332.

[107] C.Y. Liao, J.J. Fu, J.B. Shi, Q.F. Zhou, C.G. Yuan, G.B. Jiang, Environ. Toxicol. Pharmacol. 22 (2006) 225

[108] M.L.A. Cuvin-Aralar, R.W. Furness, Ecotoxicol. Environ. Saf. 21 (1991) 348.

[109] J.H. Koeman, W.H. Peeters, C.H. Koudstaal-Hol, P.S. Tjioe, J.J.D. Goeij, Nature 245 (1973) 385.

[110] K. Aoshima, M. Kasuya, Toxicol. Lett. 6 (1980) 181.

[111] A. Wang, D. Barber, C.J. Pfeiffer, Arch. Environ. Contam. Toxicol. 41 (2001) 403.

[112] C.Y. Liao, Q.F. Zhou, J.J. Fu, J.B. Shi, C.G. Yuan, G.B. Jiang, Environ. Toxicol. 22 (2007) 69.

[113] http://www.pesticideinfo.org/Index.html.

[114] I. Lopes, D.J. Baird, R. Ribeiro, Environ. Toxicol Chem. 23 (2004) 1702.

[115] J.L.T. Pestana, A. Re, A.J.A. Nogueira, A.M.V.M. Soares, Chemosphere 68 (2007) 1556.

[116] C.M. Liao, C.M. Lin, L.J. Jou, K.C. Chiang, Environ. Pollut. 147 (2007) 656.

[117] G.N. Mhatre, S.B. Chaphekar, Environ. Pollut. Series A Ecol. Biol. 39 (1985) 207.

[118] SEPA, GB/T 12990-91, Water quality-Microbial community biomonitoring-PFU method.

[119] M.S. Henebry, J. Cairns Jr., Trans. Am. Micro. Soc. 99 (1980) 151.

[120] J. Cairns Jr., J.L. Plafkin, R.L. Kaesler, R.L. Lowe, J. Protozool. 31 (1983) 47

[121] C.S. Yang, W.S. Shu, R. Xu, Z. Lan, Environ. Pollut. Control. $22(2000) 20$.

[122] J.L. Clark, W.H. Clements, Environ. Toxicol. Chem. 25 (2006) 2306.

[123] C.D.C. Primo, Environ. Toxicol. Chem. 22 (2003) 2952.

[124] V. Axiak, D. Micallef, J. Muscat, A. Vella, B. Mintoff, Environ. Int. 28 (2003) 743.

[125] S. Qi, M.X. Lin, K.H. Li, Acta Scientiae Circumstantiae 3 (1982) 181

[126] C.M. Liao, L.J. Jou, C.M. Lin, K.C. Chiang, C.H. Yeh, B.Y.H. Chou, Environ. Toxicol. 22 (2007) 295.

[127] W.X. Wang, P.S. Rainbow, Environ. Chem. 3 (2006) 395.

[128] J.A. Fernandez, M.D. Vazquez, J. Lopez, A. Carballeira, Environ. Pollut. 139 (2006) 21.

[129] L. Croisetiere, L. Hare, A. Tessier, S.D. Duchesne, Environ. Sci. Technol. 39 (2005) 3056.

[130] M.J. Sanders, H.H. Du Preez, J.H.J. Van Vuren, Ecotox. Environ. Safe. 41 (1998) 203.

[131] J.M. Besser, W.G. Brumbaugh, T.W. May, C.J. Schmitt, Environ. Monit. Assess. 129 (2007) 227.

[132] Z.Q. Feng, M.H. Ma, C.J. Guan, Z.H. Bian, F.G. Lin, Mar. Environ. Sci. 19 (2000) 50.

[133] R.Q. Yang, Q.F. Zhou, J.Y. Liu, G.B. Jiang, Food Chem. 97 (2006) 637.

[134] M. Das, S.K. Maiti, Asian J. Water Environ. Pollut. 4 (2007) 169.

[135] M.N.V. Prasad, H.M. Freitas, Electronic J. Biotechnol. 6 (2003) 285.

[136] M. Kalin, W.N. Wheeler, G. Meinrath, J. Environ. Radioactivity 78 (2005) 151.

[137] W.H. Hou, X. Chen, G.L. Song, Q.H. Wang, C.C. Chang, Plant Physiol. Biochem. 45 (2007) 62

[138] S. Srivastava, S. Mishra, R.D. Tripathi, S. Dwivedi, Aquat. Toxicol. 80 (2006) 405 
[139] D.T. Rhea, D.D. Harper, A.M. Farag, W.G. Brumbaugh, Environ. Monit. Assess. 115 (2006) 381.

[140] W.P. Norwood, U. Borgmann, D.G. Dixon, Environ. Pollut. 147 (2007) 262.

[141] J.H. Yim, K.W. Kim, S.D. Kim, J. Hazard. Mater. 138 (2006) 16.
[142] O. Perceval, Y. Couillard, B. Pinel-Alloul, A. Giguere, P.G.C. Campbell, Aquat. Toxicol. 69 (2004) 327.

[143] I. Ahmad, V.L. Maria, M. Oliveira, M. Pacheco, M.A. Santos, Mutation Res. Genet. Toxicol. Environ. Mutagen. 608 (2006) 16. 